\title{
DISENFRANCHISEMENT IN LINGUISTICALLY DIVERSE SOCIETIES: THE CASE OF THE EUROPEAN UNION
}

Victor Ginsburgh
ECARES, Free University of Brussels

Ignacio Ortuño-Ortín

University of Alicante

\section{Shlomo Weber}

Southern Methodist University, CORE, and Catholic University of Louvain

\begin{abstract}
We consider a linguistically diversified society and examine the notion of language disenfranchisement when some individuals are denied the full access to documents and political process in their native tongues. To calculate the disenfranchisement indices we use the Dyen percentage cognate matrix of linguistic distances between Indo-European languages and apply survey and population data on language proficiency in the European Union. We then determine optimal sets of official languages that depend on society's sensitivity against disenfranchisement and comprehensiveness of the chosen language regime. We also discuss the language situation in the European Union after its last enlargement. (JEL: D70, O52, Z13)
\end{abstract}

\section{Introduction}

The challenges of multilingual societies are well documented over the course of human history. The most famous example is the consequence of the attempt of the "people" to build a tower in Shinar (Babylonia) to be closer to the sky. God disliked the idea, descended and "confuse[d] their speech, so that one person will not understand another's speech. God scattered them all over the face of the earth, and they stopped building the city" (Genesis 11,1-9). The difficulties in modern societies are by no means smaller, the main reason being that "like religion, language does not lend itself easily to compromise" (Laponce 1992, pp. 599-600).

In this paper we consider a model of a society where individuals are distinguished on the basis of their language characteristics. There is a set of existing languages and every member of the society is characterized by her language skills represented by all the languages in which she is proficient. The problem faced by

Acknowledgments: We wish to thank Philippe Van Parijs for useful insights and two anonymous referees of this journal for very valuable comments and suggestions. We are grateful to the Alexander von Humboldt Foundation and Fundación BBVA for their financial support.

E-mail addresses: Ginsburgh: vginsbur@ulb.ac.be; Ortuño-Ortín: ortin@merlin.fae.ua.es; Weber: weber@core.ucl.ac.be 
the society is to select a subset of languages to be used for translation of official documents, communication between institutions and citizens, debates in official bodies, and so forth.

The choice of official languages may have a major impact on the well-being of some individuals since it will limit their access to laws, rules, and regulations. In some cases, these limitations could even violate the basic principles of the society. For example, in the European Union "citizens must be able to take part in building and maintaining the Union. They have a right to participate on equal terms and must have access to information and legal texts in their national languages that affect their lives" (Schaerer 2003). Article 2.11 of the Amsterdam Treaty allows every citizen of the Union to use his native language in dealing with the official institutions of the EU. Noninclusion of some languages in the set of the official ones goes beyond restrictions on the access to information. It may also alienate groups of individuals whose cultural, societal, and historical values and sensibilities are not represented by the official languages and consequently create "language disenfranchisement." In the context of the European Parliament, "the right of an elected Member to speak, read, and write in his or her own language lies in the heart of Parliament's democratic legitimacy. The case for multilingualism is based not only on fairness to Members, from whichever country they are elected. It is necessary to ensure the support of citizens in all Member states; if Parliament does not recognize their language, it is less likely that citizens will recognize it as being their Parliament" (see Report of Secretary General, document PE 305.269/ BUR/fin, 2001).

However, the cost of services required to maintain a larger number of official languages ${ }^{1}$ languages could be quite substantial. Even before the 2004 enlargement the institutions of the European Union were the largest recruiter of interpreters and translators in the world (Cole and Cole 1997, p. 59). In 1999 the total translation and interpretation costs for the Commission alone amounted to $30 \%$ of its internal budget (De Swaan 1993; and 2001, p. 172). The basic principles of political accountability and equality among citizens require that all, or at least a substantial part of the full-fledged translation services, will have to be maintained in some of the EU institutions (Council of the European Union, European Council, European Parliament) (Mamadouh 1995, p. 55-56; Council of the European Union 2002). Moreover, a failure to provide translation services by the EU would simply shift the provision of the service to individual countries, leading to duplications that may raise the total cost of services (Mamadouh and Hofman 2001), as well as to divergent translations

1. In this paper we use the term "official language" rather than "working language", but the distinction between these two concepts in the EU is not very clear. For example, in their first ever passed Regulation in 1958, the Council of Ministers of the European Community establishes the distinction between the two but no definition is provided. See Mamadouh (1995, p. 4). Currently, the European Union has eleven official and working languages, Danish, Dutch, English, Finnish, French, German, Greek, Italian, Portuguese, Spanish, Swedish, and one treaty language, Irish. 
and interpretations. The burden of maintaining official languages is not limited to direct costs of translation and interpretation. Communication (De Swaan 2001, p. 173) constitutes an even more serious challenge in societies with a large number of official languages. Translation and interpretation errors as well as the delays caused by translations may end up paralyzing multilateral discussions and negotiations (Mamadouh 1998, p. 8). But more importantly, language is so much associated to local culture that large subsets of the population may become, at best, insensitive, at worst opposed to the political process. As Bretton (1976, p. 447) points out: "Language may be the most explosive issue universally and over time. This mainly because language alone, unlike all other concerns associated with nationalism and ethnocentrism ... is so closely tied to the individual self. Fear of being deprived of communicating skills seem to rise political passion to a fever pitch."

Unless the set of official languages includes all languages, a linguistically diversified society is bound to face some degree of language disenfranchisement. An important feature of our analysis is that an individual derives her degree of disenfranchisement over the set of official languages as a whole, rather than dissecting it into preferences over single languages and we define the preferences of every member of the society over all subsets of languages. This has important implications on the selection of optimal sets of official languages. For example, there are more citizens in the EU who speak German than French. However, this fact alone does not necessarily support the choice of German over French as one of the official languages. Indeed, the number of EU citizens who speak both English and French is larger than the number of those who speak English and German. Thus, preferences over larger sets of languages, especially those including English, could be more relevant and informative than preferences over single languages.

We calculate disenfranchisement using two alternative methods. One is dichotomous: An individual is disenfranchised if she speaks no official language; she is not if she speaks at least one official language. This assumption can be challenged: If an individual does not speak any official language, some of them may have common roots with her native tongue that would reduce the degree of her disenfranchisement. Indeed, consider a citizen who speaks only Portuguese and compare her attitude towards two potential sets of official languages, containing respectively Spanish or German. Even though our Portuguese citizen speaks none of these, given the cultural and linguistic proximity of Portuguese and Spanish, the degree of her linguistic disenfranchisement will be lower if Spanish rather than German is chosen as one of the official languages. This leads to what we call the Dyen ${ }^{2}$ disenfranchisement index.

2. The term refers to Isidore Dyen who led the research for collecting the data and for computing such distances. 
Both indices can be computed using two basic data sets on the number of people who do (or do not) speak languages. First, we compute disenfranchisement indices and optimal language sets using country populations and their native language only. To account for multilingual citizens, we also use surveys on language proficiency in each country.

We also examine optimal sets of official languages, which are determined by two parameters. One is the sensitivity of the society towards language disenfranchisement of its members. The other is the degree of comprehensiveness of its language regime, which can take any intermediate form between the following two polar cases. Under full interpretation all documents and discussions in meetings are translated into all languages. Under minimal interpretation, nothing is translated. In practice, the language regime is chosen somewhere between these two extremes. This is already the case in the European Union today, where only some documents are translated into all official languages and the discussions (and translations) in several elected bodies are limited to a small number of languages.

There are other examples: (a) In the European Court of Justice the language of the hearings is chosen by the defendant (among 11 official languages plus Irish) at beginning of the procedure, and the proceedings are translated into French, the permanent working language of the Court; (b) Even though the Commission publishes its official documents in all official languages, its internal working languages are French and English, and to a lesser extent German. See Mamadouh (1998, p. 5); (c) It is often suggested to use some pivotal languages in the Parliament, to which and from which all other languages that are used in the Parliament will be translated.

The paper is organized as follows. In Section 2, we discuss our model and introduce language disenfranchisement indices. Section 3 is devoted to the two important special cases of disenfranchisement indices based on distances between languages: dichotomous disenfranchisement and Dyen disenfranchisement. In Section 4, we compute our indices and show that they lead to similar results. The two main groups of European languages (Latin and Germanic) have to be represented in order to reduce disenfranchisement in the EU15. We extend our analysis to the Union after the enlargement using the population based disenfranchisement indices. In Section 5, we derive the optimal sets of official languages for different values of sensitivity towards language disenfranchisement and comprehensiveness of the language regime. We show that the introduction of the Dyen matrix of linguistic distances has a major impact on our results. In particular, it highlights the importance of Latin languages, such as French, Spanish, or Italian. It may come as a surprise that the pair of two major European languages, English and German, generates more disenfranchisement than Spanish and Dutch. The reason is that proximity dominates the effect of number of native speakers, as in the case of the linguistic closeness of French, Italian, and Portuguese to Spanish, and of 
Dutch to German. Section 6 contains some concluding remarks. The theoretical derivations utilized in Section 4 are presented in the Appendix.

\section{The Model}

We consider a society $N$ that consists of $n$ members, ${ }^{3}$ who speak different languages from a given set $\mathcal{L}=\{1, \ldots, L\}$. For every individual $i \in N$ we denote by $P(i)$ the subset of languages in $\mathcal{L}$ spoken by $i{ }^{4}$

Given a set of official languages $T$, those members of the society who speak no language from $T$ will be disenfranchised. However, an empty intersection of the sets $P(i)$ and $T$ may be insufficient to determine the degree of disenfranchisement of individual $i$. As alluded to in the introduction, a unilingual Portuguese speaker who speaks neither German nor Spanish may prefer the set which contains Spanish. To account for this possibility, we introduce the distance function $\Gamma$, defined over pairs of subsets of languages, where $\Gamma\left(S, S^{\prime}\right)$ indicates how "linguistically close" the sets $S$ and $S^{\prime}$ are. Thus, for every set of languages $T$, the value $\Gamma(P(i), T)$, the distance between the set of languages $P(i)$ spoken by $i$ and the set $T$, will be considered as a degree of (individual) language disenfranchisement of individual $i$. Thus, if the set $T$ is chosen as the set of official languages, the aggregate disenfranchisement index, $D^{\Gamma}(T)$, is defined by:

$$
D^{\Gamma}(T)=\sum_{i \in N} \Gamma(P(i), T)
$$

Note that for every distance function $\Gamma$, the disenfranchisement index $D^{\Gamma}$ decreases if the set of official languages expands:

$$
T \subset S \rightarrow D^{\Gamma}(T)>D^{\Gamma}(S)
$$

where $T \subset S$ means that the set $T$ is contained in the set $S$ and is different from $S$. That is, a more inclusive set of official languages reduces disenfranchisement. Thus, if the reduction of disenfranchisement is the only goal of the society, the entire set of languages $\mathcal{L}$ would be the unambiguous choice. In this case only individuals who speak no language in $\mathcal{L}$ would contribute to disenfranchisement. However, cost considerations for maintaining official languages make the choice of the optimal set more complicated. Denote by $C(T)$ the cost of maintaining the

3. We use the word "society" here in order to encompass communities, regions, countries, continents, or any other political and geographical structure.

4. We do not distinguish here between native and nonnative tongues, and, more generally, we do not introduce the degree of command of a certain language, which is anyway very difficult to assess. 
set $T$ of official languages and assume that the cost function increases if the set of official languages expands:

$$
T \subset S \rightarrow C(T)<C(S) .
$$

Thus, there is a trade-off between disenfranchising citizens and the translation, interpretation, and communication costs generated by a large number of languages. Formally, the society's objective is to find a set of languages $T$ that minimizes the weighted sum of the total disenfranchisement index $D^{\Gamma}(T)$ and the cost $C(T)$ :

$$
\min _{T \subset \mathcal{L}} \alpha D^{\Gamma}(T)+C(T)
$$

where the positive parameter $\alpha$ represents the society's "sensitivity" parameter attached to members' disenfranchisement. ${ }^{5}$

Let us turn to a brief examination of the cost function. There are cases in which the proper functioning of official institutions becomes impractical if too many languages are used. Imagine a meeting where every participant speaks his own language without being understood by the majority of other participants. This generates a cost function whose values are prohibitively high if the number of official languages exceeds a certain threshold. But even if this is not the case, the total cost of sustaining several languages depends on the nature of the language regime imposed by the society. Assume that there is a fixed cost $c$ generated by translation, interpretation, communication, and printing of all documents between any two official languages and that there is a uniform stream of demands from all languages. Under a "full interpreting regime" that requires every important document to exist in all official languages, the total cost of sustaining $k$ languages would be given by $c k^{2}$. If the society adopts a "minimal standard interpreting regime," that requires no translation into any other official language, the total cost of sustaining $k$ languages will be $c k$. The society can also adopt an "intermediate standard interpreting regime," in which case the cost would take values $c k^{\beta}$, where $1<\beta<2$. To accommodate various language regimes, we assume that $C(T)=c|T|^{\beta}$, where $|T|$ stands for the cardinality of the set $T$, and the parameter $\beta(1 \leq \beta \leq 2)$ represents the degree of comprehensiveness of the language regime, including two polar cases $\beta=1$ and $\beta=2$. Without loss of generality, we set $c=1$. Then the society's problem is to choose $T$ that solves

$$
\min _{T \subset \mathcal{L}} G^{\Gamma}(T, \alpha, \beta)
$$

5. See also Grin (2003) who argues that there must be an optimum, since "it is reasonable to assume that the benefits of diversity increase at a decreasing rate, while its costs increase at an increasing rate." As one of the referees has suggested, along these lines one can introduce a societal objective function that is strictly concave, rather than linear, in $D^{\Gamma}(T)$. In our attempt to keep this analysis as simple as possible, we leave this extension to the future research. 
where

$$
G^{\Gamma}(T, \alpha, \beta) \equiv \alpha D^{\Gamma}(T)+|T|^{\beta} .
$$

The following proposition is straightforward.

Proposition 1. (i) The function $G^{\Gamma}(T, \alpha, \cdot)$ is increasing in $\beta$ for every $T$ and $\alpha$. That is, raising the standard of the interpreting regime increases society's language costs. (ii) The function $G^{\Gamma}(T, \cdot, \beta)$ is increasing in $\alpha$ for every $T$ and $\beta$.

For every $\alpha$ and $\beta$, let the solutions of problem (1) be denoted by $T^{\Gamma}(\alpha, \beta)$ and assume that they are well defined. We have the following observation:

Proposition 2. There exists $\alpha^{*}$ such that $T^{\Gamma}(\alpha, \beta)=\mathcal{L}$ for every $1 \leq \beta \leq 2$ whenever $\alpha>\alpha^{*}$. That is, if the society exhibits a sufficiently high degree of intolerance to disenfranchisement, no language should be excluded from the list of official languages.

Note that the second term in equation (2) depends only on the number of languages in $T$. Thus, if the examination is restricted to sets of languages that consist of $k \leq L$ elements, the task is reduced to identifying those $k$ languages that minimize disenfranchisement. ${ }^{6}$ Indeed, let $k$ be given. Denote

$$
T_{k}^{\Gamma}=\arg \min _{|T|=k} D^{\Gamma}(T) .
$$

Then the optimal set $T^{\Gamma}(\alpha, \beta)$ is determined by:

$$
T^{\Gamma}(\alpha, \beta)=\arg \min _{k=1, \ldots, L} G^{\Gamma}\left(T_{k}^{\Gamma}, \alpha, \beta\right) .
$$

In the next section we investigate the solutions of problem (1).

\section{Dichotomous and Dyen Disenfranchisement Indices}

Let us assume that for any two sets of languages $S$ and $S^{\prime}$, the distance function $\Gamma\left(S, S^{\prime}\right)$ takes values between 0 and 1 and that $\Gamma\left(S, S^{\prime}\right)=0$ only if $S$ and $S^{\prime}$ contain a common language. If either $S$ or $S^{\prime}$ is empty, we set $\Gamma\left(S, S^{\prime}\right)=1$. We consider two special cases.

6. This is what Van Parijs (2003) calls "the principle of minimal exclusion" for single languages. 


\subsection{Dichotomous Case}

Here the value of the distance function, denoted $\Gamma^{d}(S, T)$, is equal to 1 for every two sets $S$ and $S^{\prime}$ with an empty intersection. That is,

$$
\Gamma^{d}\left(S, S^{\prime}\right)=\left\{\begin{array}{lll}
0 & \text { if } & S \bigcap S^{\prime} \neq \emptyset \\
1 & \text { if } & S \bigcap S^{\prime}=\emptyset
\end{array}\right.
$$

Given the set of official languages $T$, the only factor in determining the degree of disenfranchisement of individual $i$ is whether she speaks a language from $T$ or not, and no consideration is given to languages that $i$ does not speak. This formulation leads to a dichotomous disenfranchisement index, denoted $D^{d}(T)$, which represents the number of members who do not speak a language in $T$ :

$$
D^{d}(T)=\sum_{\{i \in N: P(i) \cap T=\emptyset\}} 1 .
$$

\subsection{Dyen Case}

If an individual speaks at least one official language, she is not disenfranchised, that is, the degree of her disenfranchisement is equal to zero. However, if she speaks none of the official languages, her degree of disenfranchisement may depend on the linguistic proximity between the set of languages that she speaks and the set of official languages. To account for this important feature, we consider the linguistic function $\Gamma^{y}$, derived from the matrix of "percentage cognate" IndoEuropean languages constructed by Dyen, Kruskal, and Black (1992). ${ }^{7}$ The matrix consists of the distances $y(l, m)$ between any two languages $(l, m) \in \mathcal{L}$. They take values between 0 and 1 , with $y(l, m)=0$ if and only if $l=m$. For two sets $S$ and $S^{\prime}$, the value of the linguistic distance function $\Gamma^{y}\left(S, S^{\prime}\right)$ is then determined as the minimal distance between languages in $S$ and $T$ :

$$
\Gamma^{y}(S, T)=\min _{l \in S, m \in T} y(l, m) .
$$

The corresponding Dyen disenfranchisement index $D^{y}(T)$ is the sum of Dyen distances between the language sets $P(i)$ of all members of the society and the set of official languages $T$ :

$$
D^{y}(T)=\sum_{\{i \in N: P(i) \bigcap T=\emptyset\}} y(P(i), T) .
$$

Since for every $i$ who speaks a language that belongs to $T$, the linguistic distance $y(P(i)),(T)$ is equal to zero, it follows that the Dyen index is, in fact, the sum

7. This matrix is actually the inverse to the resemblance function of Greenberg (1956). 


\begin{tabular}{lcc}
\hline & Dichotomous & Dyen \\
\hline Survey-based data & $D_{s}^{d}$ & $D_{s}^{y}$ \\
Population-based data & $D_{p}^{d}$ & $D_{p}^{y}$ \\
\hline
\end{tabular}

of the Dyen linguistic distances between the set $T$ and the language sets $P(i)$ for all those individuals who speak no language from $T$. This is in contrast to the dichotomous index that counts them as one.

\section{Computing Disenfranchisement Indices}

The disenfranchisement indices $D^{d}$ and $D^{y}$ are computed by using two sets of data. The first is a survey on language proficiency. Since some doubt is often cast on such surveys, we also calculate two indices with respect to native populations of each country. In the latter case we assume, for simplicity, that the entire population of each country (or region, as in the case of Belgium) speaks its unique official language. Our derivations lead to four indices exhibited in Table 1.

\subsection{Survey-Based Disenfranchisement}

In 2000, the Directorate of Education and Culture of the European Union ordered a survey on languages, that was conducted by INRA (2000). In each of the 15 thenmembers of the EU, 1,000 interviews ${ }^{8}$ were conducted on the use of languages. The information used in this paper is derived from answers to the following two questions:

(a) What is your mother tongue? (note to the interviewer: do not probe; do not read [the list of languages] out; if bilingual, state both languages);

(b) What other languages do you know? (show card (containing a list of languages $)^{9}$ read out; multiple answers possible).

There were four possible choices for (b). We assumed that the first two choices that came to the mind of the person interviewed were the languages that she knew best. There were also questions on whether the knowledge of the language was "very good," "good," or "basic," but we did not take these answers into account, since such qualifications are usually very subjective, vary across individuals, and are therefore not very informative. ${ }^{10}$

8. With some minor variations: 1,300 interviews in the UK, 2,000 in Germany, and 600 in Luxembourg.

9. Danish, German, French, Italian, Dutch, English, Spanish, Portuguese, Greek, Irish, Swedish, Finnish, Luxembourgish (one of the official languages of Luxembourg), Arabic, Turkish, Chinese, Sign language, Other (specify first and second), and None.

10. The examination of language knowledge in this type of surveys is open to a criticism. Nonnative speakers of a language do not use the right idiomatic expressions, mistranslate, misinterpret the real 
TABLE 2. Number of EU citizens who know only 1, 2, or 3 languages in $\mathcal{L}$.

\begin{tabular}{lclc}
\hline Languages & $\begin{array}{c}\text { No. of speakers } \\
\text { (in millions) }\end{array}$ & Languages & $\begin{array}{c}\text { No. of speakers } \\
\text { (in millions) }\end{array}$ \\
\hline E & 58.7 & EGF & 19.2 \\
G & 40.9 & EGI & 2.1 \\
F & 35.4 & EGS & 2.0 \\
I & 27.1 & EGD & 7.9 \\
S & 22.4 & EFI & 11.5 \\
D & 4.2 & EFS & 13.3 \\
EG & & EFD & 4.4 \\
EF & 37.9 & EIS & 1.5 \\
EI & 24.7 & EID & 0.3 \\
ES & 11.4 & ESD & 0.1 \\
ED & 10.8 & GFI & 1.0 \\
GF & 2.8 & GFS & 0.6 \\
GI & 2.2 & GFD & 2.0 \\
GS & 0.9 & GIS & 0.1 \\
GD & 0.5 & GID & ng \\
FI & 1.1 & GSD & ng \\
FS & 7.8 & FIS & 0.8 \\
FD & 3.6 & FID & 0.1 \\
IS & 1.1 & FSD & 0.1 \\
ID & 0.4 & ISD & ng \\
SD & ng & & \\
\hline
\end{tabular}

Notes: "ng" means less than 005 million E = English, F = French, G = German, I = Italian, $\mathrm{S}=$ Spanish, and $\mathrm{D}=$ Dutch

In order to derive disenfranchisement indices, we need some notation. For every subset $T$ of the set of languages $\mathcal{L}$, we denote by $n^{E}(T)$ the number of individuals who speak all languages in $T$ and no other language:

$$
n^{E}(T)=|\{i \in N: P(i)=T\}| .
$$

However, the survey results are given in terms of the number of individuals, denoted by $n^{A}(T)$, who speak all the languages in $T$ and, possibly, some others:

$$
n^{A}(T)=|\{i \in N: T \subseteq P(i)\}| .
$$

Obviously, for every $T$, the inequality $n^{E}(T) \leq n^{A}(T)$ holds. The derivation of the values $n^{E}(T)$ from those of $n^{A}(T)$ is presented in the Appendix.

To adjust the survey results to our framework, we consider the set $N$ of the residents of the European Union, and restrict our attention to the set $\mathcal{L}$ of six languages

meaning of words or sentences (Piron 1994, p. 67). To be known, a language needs 12,000 hours of study and practice (Piron 1994, p. 79) and a survey like the one we use certainly exaggerates the number of people who speak the language in some depth. Our argument for using the survey is twofold. First, it contains numbers, which are better than the usual guesswork on which discussions on knowledge of languages and the decisions that may follow, are based (Fettes 1991, Piron 1994, p. 69, and Crystal 1997, p. 55-61). Second, this is the most complete and recent data set that exists, and unless one has 15,000 people taking linguistic exams in several languages, it will be difficult to do any better. 
TABLE 3. The Dyen matrix of linguistic distances.

\begin{tabular}{lcccccccccc}
\hline & $\mathrm{Dk}$ & $\mathrm{D}$ & $\mathrm{E}$ & $\mathrm{F}$ & $\mathrm{G}$ & $\mathrm{Gr}$ & $\mathrm{I}$ & Po & $\mathrm{S}$ & $\mathrm{Sw}$ \\
\hline $\mathrm{Dk}$ & 0 & 0.337 & 0.407 & 0.759 & 0.293 & 0.817 & 0.737 & 0.750 & 0.750 & 0.126 \\
$\mathrm{D}$ & 0.337 & 0 & 0.392 & 0.756 & 0.162 & 0.812 & 0.740 & 0.747 & 0.742 & 0.308 \\
$\mathrm{E}$ & 0.407 & 0.392 & 0 & 0.764 & 0.422 & 0.838 & 0.753 & 0.760 & 0.760 & 0.411 \\
$\mathrm{~F}$ & 0.759 & 0.756 & 0.764 & 0 & 0.756 & 0.843 & 0.197 & 0.291 & 0.291 & 0.756 \\
$\mathrm{G}$ & 0.293 & 0.162 & 0.422 & 0.756 & 0 & 0.812 & 0.735 & 0.753 & 0.747 & 0.305 \\
$\mathrm{Gr}$ & 0.817 & 0.812 & 0.838 & 0.843 & 0.812 & 0 & 0.822 & 0.833 & 0.833 & 0.816 \\
$\mathrm{I}$ & 0.737 & 0.740 & 0.753 & 0.197 & 0.735 & 0.822 & 0 & 0.227 & 0.212 & 0.741 \\
Po & 0.750 & 0.747 & 0.760 & 0.291 & 0.753 & 0.833 & 0.227 & 0 & 0.126 & 0.742 \\
S & 0.750 & 0.742 & 0.760 & 0.291 & 0.747 & 0.833 & 0.212 & 0.126 & 0 & 0.747 \\
Sw & 0.126 & 0.308 & 0.411 & 0.756 & 0.305 & 0.816 & 0.741 & 0.742 & 0.747 & 0 \\
\hline
\end{tabular}

Notes: Since Finnish is not a Indo-European language, it is not included here Given the linguistic remoteness of Finnish, its Dyen distance to every language in the table was set equal to $1 \mathrm{Dk}=$ Danish, $\mathrm{D}=$ Dutch, $\mathrm{E}=$ English, $\mathrm{F}=$ French, $\mathrm{G}=$ German, $\mathrm{Gr}=$ Greek, $\mathrm{It}=$ Italian, Po $=$ Portuguese, $\mathrm{S}=$ Spanish, and $\mathrm{Sw}=$ Swedish

This matrix is based on cognate data collected by Isidore Dyen in the 1960s (see IE-DATA1 〈at www ntu edu au/education/langs/ielex/IE-DATA1)) For each entry from the list of 200 basic meanings selected by Swadesh (1952), and Dyen, Kruskal, and Black (1992) see collected the words used in 95 Indo-European speech varieties (languages and dialects) and classified these into cognate classes For a given meaning, such a class contains all the words from different speech varieties, that have an unbroken history of descent from a common ancestral word An entry of this matrix is equal to $n_{l m} /\left(n_{l m}^{0}+n_{l m}\right)$, the " percentage cognate" between languages $l$ and $m$, where $n_{l m}$ is the number of meanings for which $l$ and $m$ are classified as "cognate" and $n_{l m}^{0}$ is the number of meanings for which the speech varieties $l$ and $m$ are "not cognate" (The number of "doubtfully cognate" meanings does not enter into the calculation of such percentages) Note that the higher this number, the more "similar" the two languages Since we use a "distance" matrix, it is more convenient to consider the "percentage of not cognate," $y(l, m)=n_{l m}^{0} /\left(n_{l m}^{0}+n_{l m}\right)$ The diagonal elements $y(l, l)$ are set to zero

most widely spoken in the EU before the enlargement: Dutch, English, French, German, Italian, and Spanish. To simplify, we disregard the small group of individuals who know four or more languages and assume that $n^{E}(T)=n^{A}(T)=0$ if the set $T$ contains more than three languages. By using the derivations relegated to the Appendix, we obtain the values of the functions $n^{E}(\cdot)$ given in Table 2 . These values allow for the direct derivation of the dichotomous disenfranchisement indices $D_{s}^{d}(T)$ (Stroobants 2002; Ginsburgh and Weber forthcoming). Moreover, combining them with the Dyen distance matrix, given in Table 3, Dyen disenfranchisement indices $D_{s}^{y}(T)$ can be easily computed. (Both indices $D_{s}^{d}$ and $D_{s}^{y}$ are given in Table 4.)

\subsection{Population-Based Disenfranchisement}

Here we take the extreme assumption that only those citizens who live in a country speak its native language. It is quite obvious that this assumption will negatively affect native languages in less populated countries, and favor native languages in larger countries. ${ }^{11}$ Both sets of indices $D_{p}^{d}$ and $D_{p}^{y}$ are presented in Table 4.

It is worthwhile to extend the examination of population-based indices for the ten countries that have joined the Union on May 1, 2004. Detailed results are

11. English, for example, is the native language of 62.3 million inhabitants (58.6 in the United Kingdom and 3.7 in Ireland), while German is spoken by 90.1 native speakers ( 82 million Germans and 8.1 million Austrians). Even French is the native language of more citizens than English (60.4 million Frenchman and 4 million French-speaking Belgians). 


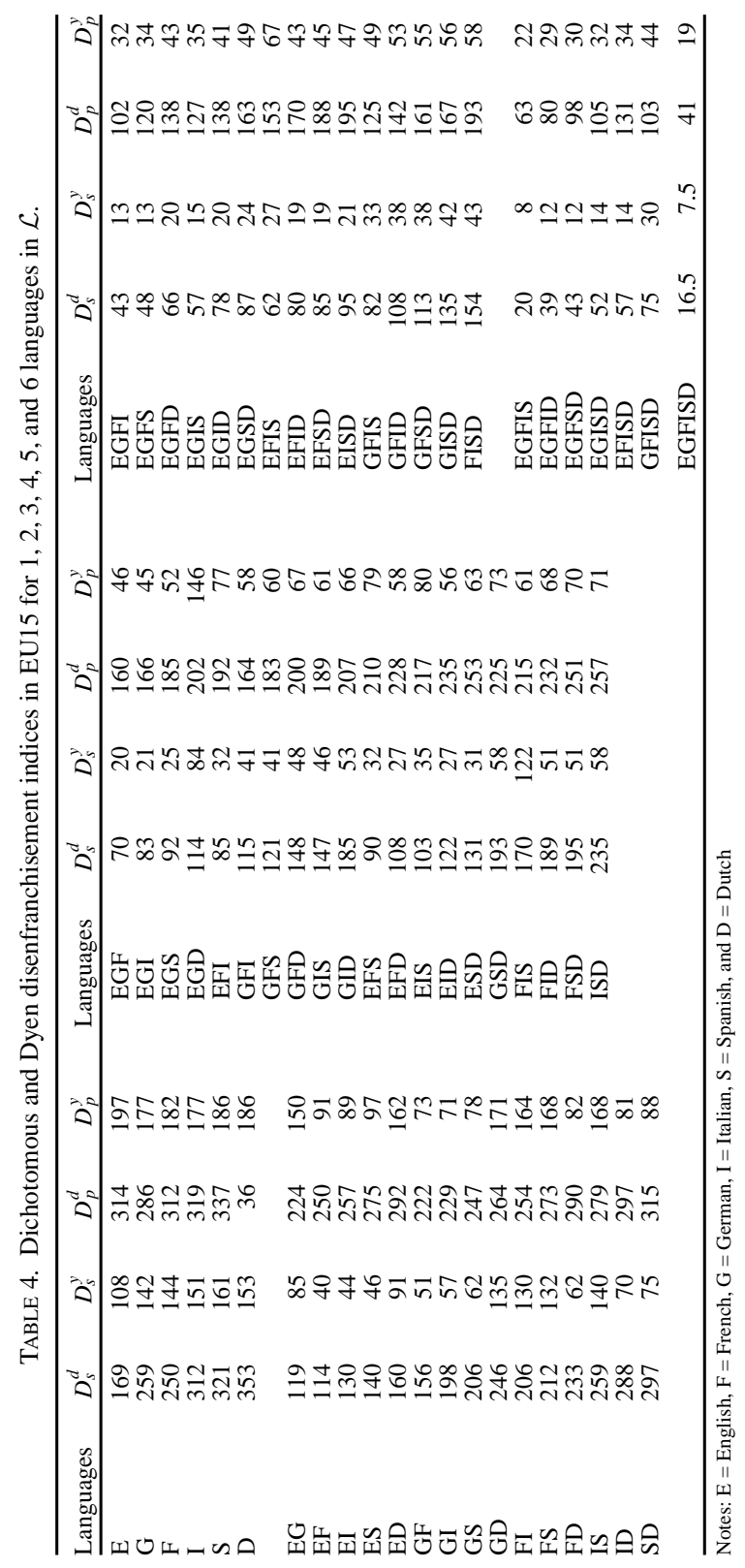


TABLE 5. Dichotomous and Dyen population-based disenfranchisement indices in EU 25, for $1,2,3,4,5$, and 6 languages in $\mathcal{L}$.

\begin{tabular}{lcccccccr}
\hline Languages & $D_{p}^{d}$ & $D_{p}^{y}$ & Languages & $D_{p}^{d}$ & $D_{p}^{y}$ & Languages & $D_{p}^{d}$ & $D_{p}^{y}$ \\
\hline E & 377 & 245 & EGF & 223 & 94 & EGFI & 165 & 79 \\
G & 349 & 224 & EGI & 229 & 92 & EGFS & 183 & 81 \\
F & 375 & 224 & EGS & 248 & 100 & EGFD & 201 & 90 \\
I & 382 & 225 & EGD & 265 & 194 & EGIS & 190 & 82 \\
S & 400 & 235 & EFI & 255 & 125 & EGID & 201 & 89 \\
D & 424 & 235 & EFS & 273 & 127 & EGSD & 226 & 96 \\
& & & EFD & 291 & 106 & EFIS & 216 & 115 \\
EG & 287 & 198 & EIS & 280 & 128 & EFID & 233 & 91 \\
EF & 313 & 140 & EID & 297 & 104 & EFSD & 251 & 93 \\
EI & 319 & 138 & ESD & 316 & 112 & EISD & 258 & 95 \\
ES & 338 & 145 & GFI & 227 & 106 & GFIS & 188 & 96 \\
ED & 355 & 210 & GFS & 245 & 108 & GFID & 205 & 100 \\
GF & 285 & 120 & GFD & 263 & 115 & GFSD & 223 & 102 \\
GI & 292 & 118 & GIS & 252 & 109 & GISD & 230 & 104 \\
GS & 310 & 126 & GID & 270 & 113 & FISD & 256 & 106 \\
GD & 327 & 218 & GSD & 288 & 121 & & & \\
FI & 317 & 212 & FIS & 278 & 109 & EGFIS & 126 & 70 \\
FS & 336 & 217 & FID & 295 & 116 & EGFID & 143 & 76 \\
FD & 353 & 131 & FSD & 314 & 118 & EGFSD & 161 & 78 \\
IS & 342 & 216 & ISD & 320 & 119 & EGISD & 168 & 79 \\
ID & 360 & 129 & & & & EFISD & 194 & 82 \\
SD & 378 & 136 & & & & GFISD & 166 & 91 \\
& & & & & & EGFISD & 104 & 66 \\
\hline
\end{tabular}

Notes: $\mathrm{E}=$ English, $\mathrm{F}=$ French, $\mathrm{G}=$ German, $\mathrm{I}=$ Italian, $\mathrm{S}=\mathrm{Spanish}$, and $\mathrm{D}=$ Dutch

provided in Table 5. German comes out as optimal choice if only one language is retained, but English and Italian are very close competitors. For three languages, the choice English-French-German is again optimal (or second-best), though the triples English-German-Italian or French-German-Italian are close substitutes.

\section{Optimal Choices of Official Languages: Empirical Analysis and Discussion}

Since for given number of official languages $k$, given value of society's sensitivity to disenfranchisement $\alpha$, and its degree of the language interpreting regime $\beta$, the solutions of the minimization problem (1) depend on disenfranchisement indices only, we can derive optimal sets $T_{k}^{\Gamma}$ in Table 6 by using the data from Table 4 . It turns out that survey-based dichotomous and Dyen first-best choices coincide. English is obvious if society restricts its choice to a single official language. If two languages are chosen, then the second language should be reasonably distant from the first and known by a reasonably large number of nonnatives. Therefore English-French is also an obvious choice, though Italian and Spanish 
TABLE 6. Optimal languages sets in EU15.

\begin{tabular}{ccccccc}
\hline & \multicolumn{7}{c}{ Number of languages } \\
\cline { 2 - 7 } & One & Two & Three & Four & Five & Six \\
\hline First best choices & & & & & & \\
Dichotomous survey-based & E & EF & EFG & EFGI & EFGIS & EFGISD \\
Dyen survey-based & 169 & 114 & 70 & 43 & 20 & 16 \\
& E & EF & EFG & EFGI* & EFGIS & EFGISD \\
Dichotomous population-based & G & GF & EFG & EFGI & EFGIS & EFGISD \\
& 286 & 222 & 160 & 102 & 63 & 41 \\
Dyen population-based & I & GI & EGI & EFGI & EFGIS & EFGISD \\
& 177 & 71 & 45 & 32 & 22 & 19 \\
Second best choices & & & & & & \\
Dichotomous survey-based & F & EG & EGI & EGFS & EGFID & \\
Dyen survey-based & 250 & 119 & 83 & 48 & 39 & \\
Dichotomous population-based & G & EI & EGI & EGIS & EGFID & \\
& 142 & 41 & 21 & 15 & 13 & \\
Dyen population-based & EG & FGI & EGFS & EGFID & \\
& G & FG & EFG & EFGS & EFGID & \\
\hline
\end{tabular}

Notes: *Ties with EFGS

$\dagger$ Ties with EGSFD

come close to French. The successive optimal choices (if society opts to go to three, four, five, and six languages) oscillate between a Germanic and a Latin language. For three, German is added, then Italian (or Spanish, which ties with Italian), then Spanish (or Italian), not because of their linguistic proximity, but because they are spoken by more citizens than Dutch, and finally, Dutch. It is also interesting to examine second-best choice sets, i.e., those with the second-lowest values of the indices. Under dichotomous disenfranchisement, the pairs EnglishFrench and English-German are very close. The Dyen index makes the choices English-French, English-Italian, and English-Spanish almost identical; and so are the triples English-French-German, English-Italian-German and EnglishSpanish-German.

As expected, population-based optimal sets are different. Indeed, English loses its lead, since German and French are spoken by more natives than English, and Italian and Spanish are linguistically closer than English and German. ${ }^{12}$ However, if the Union settles for three working languages, English, French, and German are the first-best choices according to three criteria, and is second-best according to the Dyen population-based criterion. Note, however, that French

12. The Dyen distance between Italian and Spanish is 0.212 , while it is 0.422 between English and German. See Table 3. 


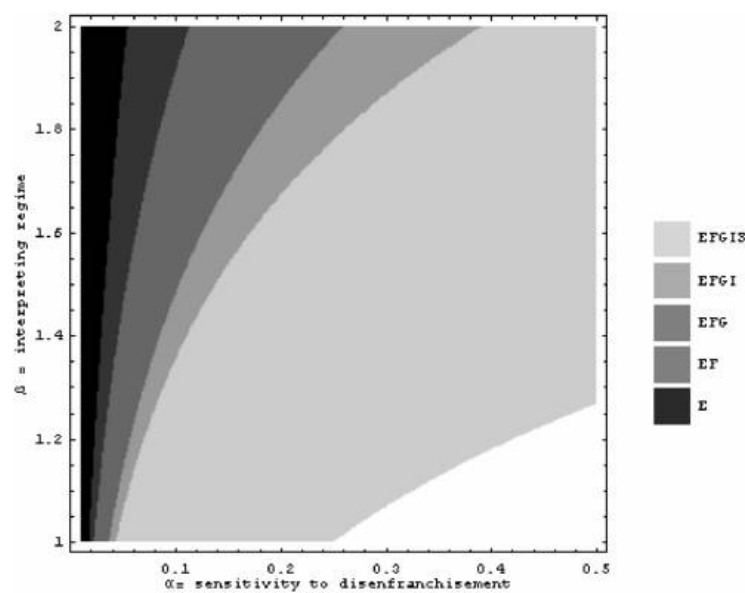

FIGURE 1. Survey-based dichotomous optimal sets: E.U. 15.

could be replaced by Italian or Spanish without substantially altering the level of disenfranchisement. ${ }^{13}$

English-French-German is the group of languages that the European Commission uses currently (though German is used to a lesser extent), and these will probably be the pivotal languages, to which and from which other languages will be translated. Our results show that this is indeed the optimal choice. Since Spanish is widely spoken in some regions outside of the EU, it could, for that reason, serve as a serious alternative to French, even though French is optimal within the European Union. ${ }^{14}$ This shows that when distances between languages are accounted for, the balance shifts towards Latin languages, providing a strong argument against English as a unique lingua franca.

Figures 1-6 illustrate the sets of optimal languages $T^{d}(\alpha, \beta)$ and $T^{y}(\alpha, \beta)$, respectively, for all values of $\alpha$ and $\beta$. The darkest area in the left of each figure represents the pairs $(\alpha, \beta)$, for which only one language (English) is chosen as

13. The results would remain almost the same if we consider the EU after the enlargement. The only difference is that instead of Italian and German being first and second best single choices according to the Dyen-population index before the enlargement, German and French lead the way.

14. French is used worldwide by 169 million people, Italian, by 70 million, and Spanish by 450 million. For Spanish see Dalby $(2002$, p. 31). For French, which is also the lingua franca in most West African countries, see $\langle$ http://www.france.diplomatie.fr/francophonie/francais/ carte.html $\rangle$, the web site of the French diplomatic service. Dalby's estimate (p. 31) is somewhat lower (130 million people "use French"). For Italian, the number comes from 〈http://www. ethnologue.com/show language.asp?code=ITN $\rangle$ (or DUT) 


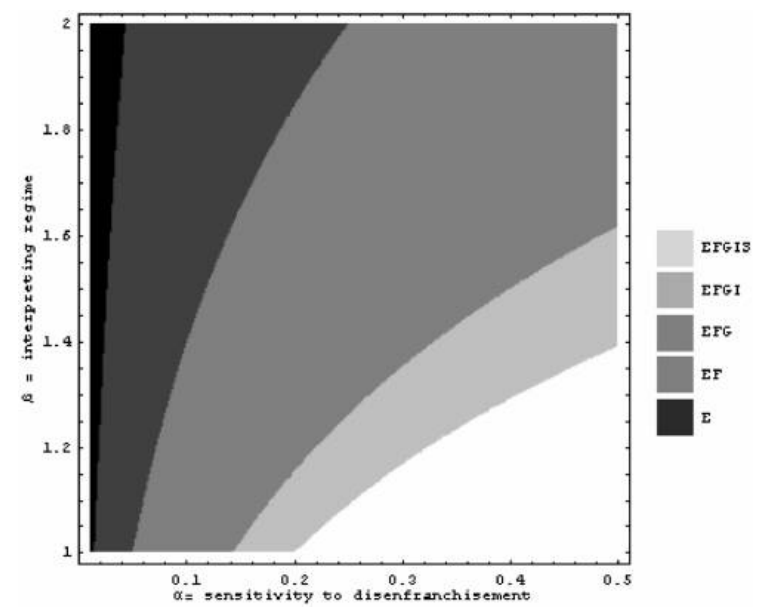

FIGURE 2. Survey-based Dyen optimal sets: E.U. 15.

the official language. The next areas to the right represent the sets of $(\alpha, \beta)$ values for which two, three, four, or five languages are optimal according to the criterion considered. Finally, in the white area, all six languages are needed. As the figures show, sensitivity to disenfranchisement $(\alpha)$ has to be very low in order

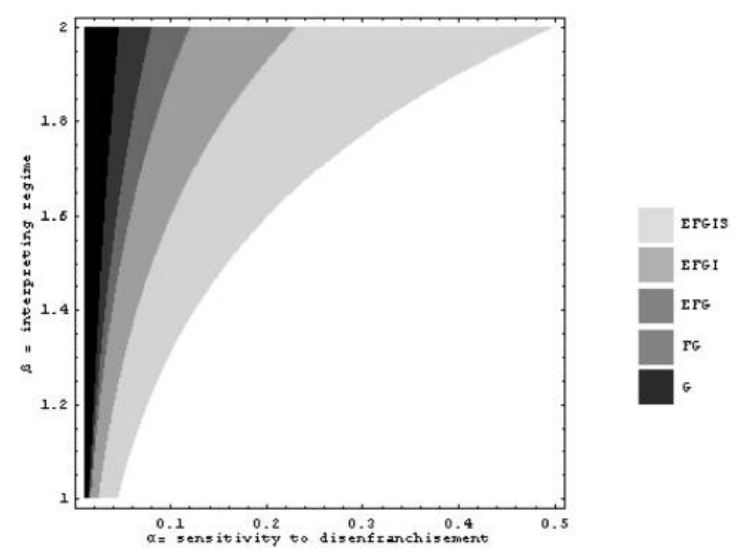

FIGURE 3. Population-based dichotomous optimal sets: E.U. 15. 


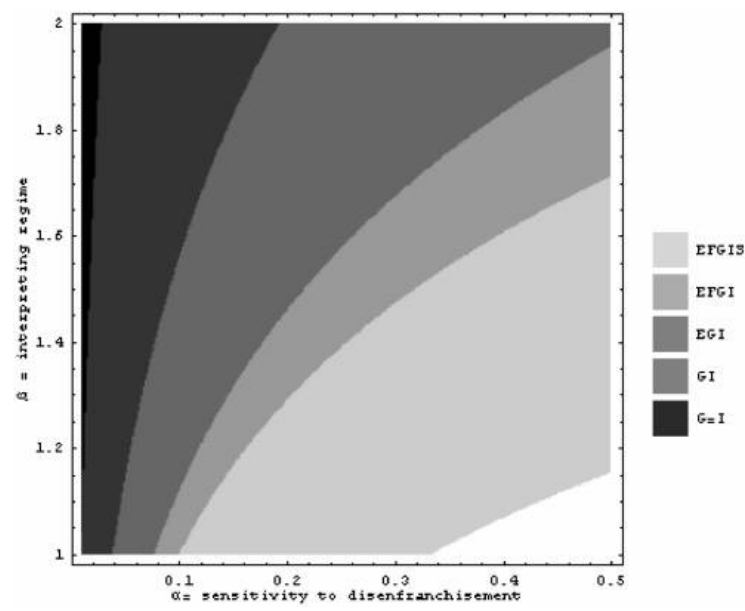

FIGURE 4. Population-based Dyen optimal sets: E.U. 15.

to sustain a unique official language for all types of interpreting regimes $(\beta)$. In general, the set of optimal languages expands under higher values of sensitivity to disenfranchisement and shrinks under a higher degree of comprehensiveness of the language regime.

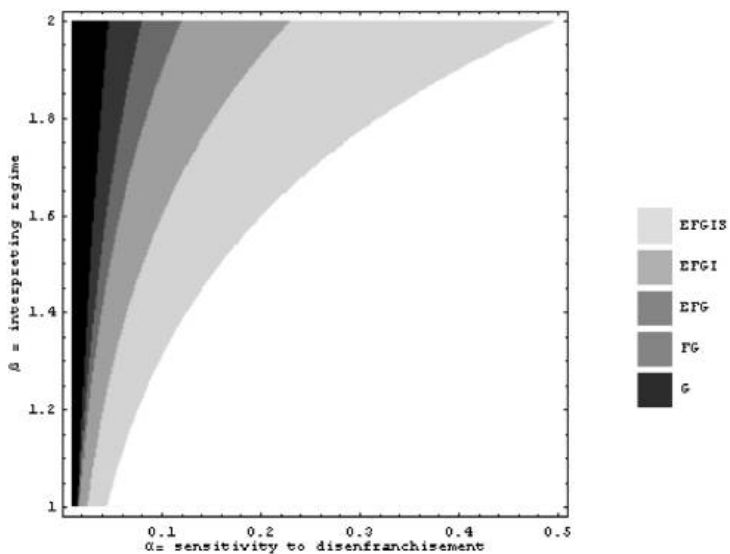

FIGURE 5. Population-based dichotomous optimal sets: E.U. 25. 


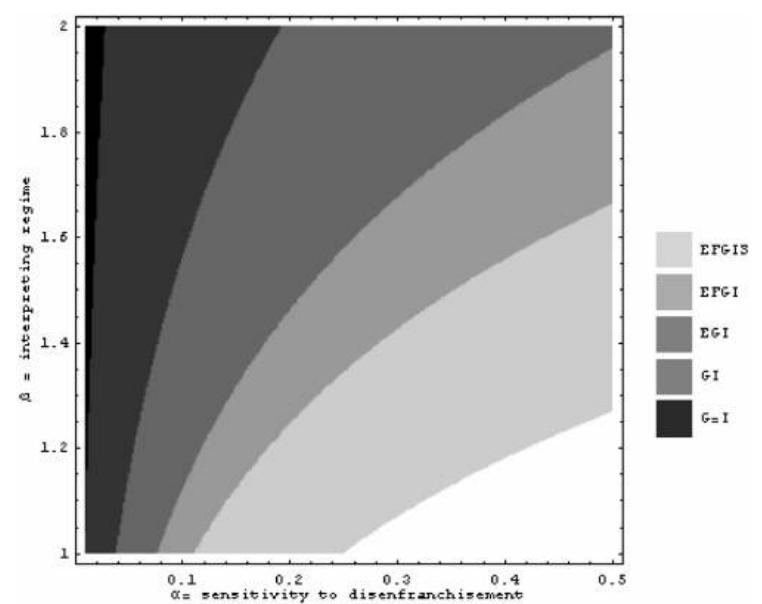

FIGURE 6. Population-based Dyen optimal sets: E.U. 25.

\section{Conclusions}

Our results show that it could be unwise to select English only as the working language, not only because it is not always optimal, but also because it is optimal only for very small values of the coefficient that represents sensitivity to disenfranchisement. What is remarkable, however, is that whatever index is chosen, the best choice of three languages is English, French, and German, though Italian could be a very reasonable substitute to French. This is so for the EU before and after the 2004 enlargement. Spanish is obviously not a good choice within the EU if no account is taken of Mexico and Latin America, and the growing importance of Spanish in the South and Western United States. It may therefore be reasonable for the EU to adopt four working languages, three of which (English, French, and German) for general use, while Spanish is added for its importance in the rest of the world.

\section{Appendix}

The following useful result allows us to derive the values $n^{E}(T)$ from those of $n^{A}(T)$.

Proposition 3. For every $T \subset \mathcal{L}$ we have

$$
n^{E}(T)=n^{A}(T)-\sum_{k=1}^{L-|T|} \sum_{S \in \mathcal{L}_{|T|+k}^{T}}(-1)^{k} n^{A}(S)
$$


where for every integer $k,|T| \leq k \leq L, \mathcal{L}_{k}^{T}$ denotes the set of all subsets of $\mathcal{L}$ that consist of $k$ elements and contain the set $T$.

Proof. Let individual $i$ be such that there is a set $S \in \mathcal{L}_{|T|+k}^{T}$ such that $S \subset P(i)$. If $k=0$ then $i$ is included once on both sides of equation (A.1). If $k>0$, then $i$ does not appear on the left side of (A.1), but is included $\left(1-\left(\begin{array}{c}k \\ 1\end{array}\right)+\left(\begin{array}{c}k \\ 2\end{array}\right)-\cdots+(-1)^{k}\left(\begin{array}{c}k \\ k\end{array}\right)\right)$ times ${ }^{15}$ which completes the proof of the proposition.

Since we ignore those individuals who speak at least four languages, equation (A.1) implies that for every $i, j, k \in \mathcal{L}$

$$
\begin{gathered}
n^{E}(\{i\})=n^{A}(\{i\})-\sum_{T \in \mathcal{L}_{2}^{\{i\}}} n^{A}(T)+\sum_{T \in \mathcal{L}_{3}^{\{i\}}} n^{A}(T), \\
n^{E}(\{i, j\})=n^{A}(\{i, j\})-\sum_{T \in \mathcal{L}_{3}^{\{i, j\}}} n^{A}(T), \\
n^{E}(\{i, j, k\})=n^{A}(\{i, j, k\}) .
\end{gathered}
$$

The values $n^{E}$ are presented in Table 2 .

\section{References}

Bretton, Henry (1976). "Political Science, Language, and Politics." In Language and Politics, edited by William M. O'Barr and Jean F. O'Barr. Mouton, The Hague.

Cole, John and Francis Cole (1997). A Geography of the European Union, 2nd ed. Routledge, London.

Council of the European Union (2002). "Use of Languages in the Council in the Context of an Enlarged Union.” Report of the Presidency, document 15334/1/02 December 6, 2002.

Crystal, David (1997). English as a Global Language. Cambridge University Press.

Dalby, Andrew (2002). Languages in Danger. The Penguin Press.

De Swaan, Abram (1993). "The Evolving European Language System: A Theory of Communication Potential and Language Competition." International Political Science Review. 14(3), 241-255.

De Swaan, Abram (2001). Words of the World. Polity Press, Cambridge, UK.

Dyen, Isidore, Joseph B. Kruskal, and Paul Black (1992). "An Indo-European Classification: A Lexicostatistical Experiment." Transactions of the American Philosophical Society, vol. 82, no. 5. American Philosophical Society, Philadelphia.

European Union (2001). "Preparing for the Parliament of the Enlarged European Union." Report of the Secretary General, document PE 305.269/BUR/fin, adopted by the Bureau on September 3, 2001.

Fettes, Mark (1991). "Europe's Babylon: Towards a Single European Language.” History of European Ideas, 13, 201-202.

Ginsburgh, Victor and Shlomo Weber (forthcoming). "Language Disenfranchisement in the European Union.” Journal of Common Market Studies.

$\overline{15 .}$ Given a set of cardinality $n,\left(\begin{array}{c}n \\ m\end{array}\right)$ denotes the number of its $m$-element subsets, where $m \leq n$. 
Greenberg, Joseph (1956). "The Measurement of Linguistic Diversity.” Language, 32, 109115.

Grin, François (2003). "On the Costs of Cultural Diversity." Working paper, University of Geneva.

INRA. (2001). Eurobaromètre 54 Special, Les Européens et les Langues, February 2001.

Laponce, J. A. (1992). "Language, and Politics.” In Encyclopedia of Government and Politics, vol. 1, edited by Mary Hawkesworth and Maurice Hogan. Routledge, London.

Mamadouh, Virginie (1995). "De Talen in het Europees Parlement (Languages in the European Parliament), ASGS Vol. 52, University of Amsterdam, Institute for Social Geography.

Mamadouh, Virginie (1998). "Supranationalism in the European Union: What About Multilingualism." Paper presented at the World Political Map Conference on Nationalisms and Identities in a Globalized World, May-nooth and Belfast, August 1998.

Mamadouh, Virginie and Kaj Hofman (2001). "The Language Constellation in the European Parliament, 1989-2004.” Report for the European Cultural Foundation, Amsterdam.

Piron, Claude (1994). Le défi des langues. L'Harmattan, Paris.

Schaerer, Rolf (2003). "Multilingualism in the Enlarged European Union and its Institutions." Report presented at a brainstorming session on languages, European Commission, Brussels, January $27-28,2003$.

Stroobants, J.-P. (2002). "Une Europe à 21 Langues, Nouveau Boulet Budgétaire pour la Commission." Le Monde, July 3, 2002, p. 6.

Swadesh, Morris (1952). "Lexicostatistic Dating of Prehistoric Ethnic Contacts." Proceedings of the American Philosophical Society, 96, 452-463.

Van Parijs, Philippe (2003). "Europe's Three Language Problems." In Multilingualism in Law and Politics, edited by Richard Bellamy, Dario Castiglione, and G. Longman. Hart, Oxford. 